\title{
Idiopathic normal-pressure hydrocephalus
}

\author{
Tina Hu MD MSc, Yuna Lee MD MEd
}

Cite as: CMAJ 2019 January 7;191:E15. doi: 10.1503/cmaj.180877

\section{Idiopathic normal-pressure hydrocephalus presents a \\ 1 diagnostic challenge \\ Although the complete triad is not seen in all cases, idiopathic normal- pressure hydrocephalus is characterized by gait dysfunction, cognitive impairment and urinary incontinence. These symptoms, however, are fre- quently encountered in older adults without the condition. ${ }^{1}$ The onset of cognitive impairment in idiopathic normal-pressure hydrocephalus, which is often insidious with slow progression, may resemble Alzheimer disease, ${ }^{2}$ but is potentially reversable. ${ }^{3}$ The prevalence varies from $0.3 \%$ to $3 \%$ among patients older than 65 years, and increases with age. ${ }^{3}$}

Gait dysfunction described as "freezing" and "magnetic" should trigger suspicion for the condition

Gait disturbance, typically the first symptom of idiopathic normalpressure hydrocephalus, is characterized by a short-stepped gait and difficulty initiating movements, resulting in postural instability and falls..$^{1,3}$ Some gait abnormalities in the condition may mimic Parkinson disease, but idiopathic normal-pressure hydrocephalus is associated with a wide gait and normal arm swing. ${ }^{3}$

\section{3}

Magnetic resonance imaging of the brain showing ventriculomegaly with no obstruction to the flow of cerebrospinal fluid supports the diagnosis

Ventriculomegaly seen on imaging may be a result of progressive cortical atrophy. However, ventriculomegaly in the absence of, or out of proportion to, sulcal enlargement and cortical atrophy increases suspicion for idiopathic normal-pressure hydrocephalus. ${ }^{1}$

A high-volume lumbar puncture can be used as a confirmatory test and to select patients for surgery

The opening pressure is normal $(8-18 \mathrm{~mm} \mathrm{Hg})$ in idiopathic normalpressure hydrocephalus. Cognitive testing and a timed gait assessment should be conducted before and 30-60 minutes after the procedure. ${ }^{2}$ Improved gait after a high-volume lumbar puncture (removal of 30-60 mL of cerebrospinal fluid) is a positive predictor of improvement with a ventriculoperitoneal shunt. ${ }^{2}$

\section{5}

\section{A prompt referral to a neurosurgeon is recommended in} selected patients

Ventriculoperitoneal shunts can improve symptoms, especially gait dysfunction, in up to $74 \%$ of patients. ${ }^{4,5}$ Early treatment within 3 months of diagnosis is associated with better outcomes. ${ }^{5}$

\section{References}

1. Relkin N, Marmarou A, Klinge P, et al. Diagnosing idiopathic normal-pressure hydrocephalus. Neurosurgery 2005;57(Suppl): S4-16.

2. Tsakanikas D, Relkin N. Normal pressure hydrocephalus. Semin Neurol 2007;27:58-65.

3. Nassar BR, Lippa CF. Idiopathic normal pressure hydrocephalus: a review for general practitioners. Gerontol Geriatr Med 2016;2:2333721416643702.

4. Gölz L, Ruppert F-H, Meier U, et al. Outcome of modern shunt therapy in patients with idiopathic normal pressure hydrocephalus 6 years postoperatively. J Neurosurg 2014;121: 771-5.

5. Andrén K, Wikkelsø $C$, Tisell M, et al. Natural course of idiopathic normal pressure hydrocephalus. J Neurol Neurosurg Psychiatry 2014;85:806-10.

\section{Competing interests: None declared.}

This article has been peer reviewed.

Affiliations: Department of Family and Community Medicine ( $\mathrm{Hu}$ ) and Division of General Internal Medicine (Lee), St. Michael's Hospital, Toronto, Ont.

Correspondence to: Tina Hu, tina.hu@mail. utoronto.ca

CMAJ invites submissions to "Five things to know about ..." Submit manuscripts online at http://mc. manuscriptcentral.com/cmaj 